\title{
Abnormal hemostatic function one year after orthotopic liver transplantation can be fully attributed to endothelial cell
}

\section{activation [version 1; peer review: 3 approved]}

\author{
Freeha Arshad ${ }^{1,2}$, Jelle Adelmeijer ${ }^{1}$, Hans Blokzijl3 ${ }^{3}$, Aad van den Berg ${ }^{3}$, \\ Robert Porte ${ }^{2}$, Ton Lisman 1,2
}

\begin{abstract}
${ }^{1}$ Surgical Research Laboratory, Department of Surgery, University of Groningen, University Medical Center Groningen, Groningen, 9700 RB, The Netherlands

${ }^{2}$ Section of Hepatobiliary Surgery and Liver Transplantation, Department of Surgery, University of Groningen, University Medical Center Groningen, Groningen, 9700 RB, The Netherlands

${ }^{3}$ Department of Gastroenterology, University of Groningen, University Medical Center Groningen, Groningen, 9700 RB, The Netherlands
\end{abstract}

V1 First published: 09 May 2014, 3:103
https://doi.org/10.12688/f1000research.3980.1

Latest published: $30 \mathrm{Jul}$ 2014, 3:103

https://doi.org/10.12688/f1000research.3980.2

\section{Abstract}

Background: The long-term risk of thrombotic and vascular complications is elevated in liver transplant recipients compared to the general population. Patients with cirrhosis are in a hypercoagulable status during and directly after orthotopic liver transplantation, but it is unclear whether this hypercoagulability persists over time.

Aim: We aimed to investigate the hemostatic status of liver transplant recipients one year after transplantation.

Methods: We prospectively collected blood samples of 15 patients with a functioning graft one year after orthotopic liver transplantation and compared the hemostatic status of these patients with that of 30 healthy individuals.

Results: Patients one year after liver transplantation had significantly elevated plasma levels of von Willebrand factor (VWF). Thrombin generation, as assessed by the endogenous thrombin potential, was decreased in patients, which was associated with increased plasma levels of the natural anticoagulants antithrombin and tissue factor pathway inhibitor. Plasma fibrinolytic potential was significantly decreased in patients and correlated inversely with levels of plasminogen activator inhibitor-1.

Conclusion: One year after liver transplantation, liver graft recipients have a dysregulated hemostatic system characterised by elevation of plasma levels of endothelial-derived proteins. Increased levels of von Willebrand factor and decreased fibrinolytic potential may (in part) be responsible for the increased risk for vascular disease seen in liver transplant recipients.

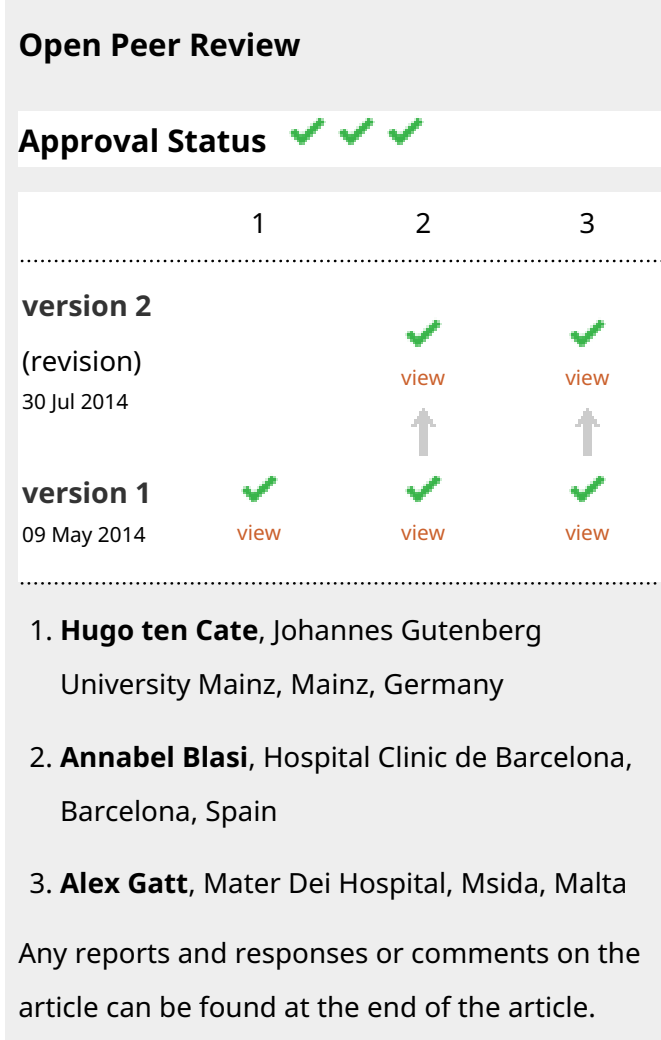


Keywords

orthotopic liver transplantation, hemostasis, hypercoagulability,

thrombotic complications

umcs This article is included in the University Medical

Center Groningen collection.

Corresponding author: Ton Lisman (j.a.lisman@umcg.nl)

Competing interests: No competing interests were disclosed.

Grant information: The author(s) declared that no grants were involved in supporting this work.

Copyright: ( 2014 Arshad F et al. This is an open access article distributed under the terms of the Creative Commons Attribution License , which permits unrestricted use, distribution, and reproduction in any medium, provided the original work is properly cited. Data associated with the article are available under the terms of the Creative Commons Zero "No rights reserved" data waiver (CCO 1.0 Public domain dedication).

How to cite this article: Arshad F, Adelmeijer J, Blokzijl $\mathrm{H}$ et al. Abnormal hemostatic function one year after orthotopic liver transplantation can be fully attributed to endothelial cell activation [version 1; peer review: 3 approved] F1000Research 2014, 3 :103 https://doi.org/10.12688/f1000research.3980.1

First published: 09 May 2014, 3:103 https://doi.org/10.12688/f1000research.3980.1 


\section{Introduction}

Patients with chronic liver disease frequently have major and multiple alterations in their hemostatic system, including a decreased platelet count and decreased plasma levels of pro- and anti-hemostatic proteins produced by the diseased liver ${ }^{1}$. The decrease in procoagulant proteins is evidenced by prolonged test results of routine coagulation assays such as the prothrombin time (PT) and activated partial thromboplastin time (APTT). Historically, due to an increased bleeding risk during surgery in combination with prolonged conventional coagulation tests and thrombocytopenia, liver disease patients were thought to be in a hypocoagulable state. In recent years it has become increasingly accepted that cirrhosis patients have a rebalanced hemostatic system which is not adequately represented by routine coagulation tests as they are only sensitive for procoagulant proteins and do not take the concomitant decrease in antihemostatic proteins into account ${ }^{2,3}$. The rebalanced hemostatic system is more fragile as compared to healthy individuals and may decompensate towards hypo- or hypercoagulability by factors such as renal failure, trauma, infection, and surgery ${ }^{1}$. Besides bleeding complications, patients with cirrhosis are also at risk for thrombotic complications and this particular clinical scenario has only recently been fully appreciated ${ }^{4-8}$.

Patients with cirrhosis who undergo orthotopic liver transplantation (OLT) show a rapid normalisation of coagulation proteins due to the intact synthetic capacity of the transplanted liver. Previous studies performed in our laboratory have shown that hemostatic capacity early after OLT appears adequate, but shows important differences when compared to healthy individuals. At 10 days after OLT, when synthetic function of the liver as assessed by PT and APTT values is adequate, multiple laboratory parameters suggest that the patients are in a hypercoagulable state. Specifically, we have shown an unbalanced von Willebrand factor (VWF)/ADAMTS13 system $^{9}$ and enhanced thrombin generation ${ }^{2}$. Also, we have shown a decreased fibrinolytic potential up to five days after surgery ${ }^{10}$.

Clinically, this hypercoagulable status is evidenced by a profoundly increased risk for thrombotic complications such as hepatic artery thrombosis (HAT). While previously HAT was assumed to be a solely surgical complication, there is emerging evidence for the involvement of the hemostatic system in the development of HAT ${ }^{11}$. In addition, liver transplant recipients are at increased risk for arterial thrombotic events. The risk for thrombotic complications remains increased months and even years after OLT compared to the general population and a substantial part of morbidity and mortality in liver transplant recipients who survive the first year after transplantation is due to vascular events ${ }^{12,13}$. Long-term vascular complications are mainly ascribed to the use of immunosuppressive medication ${ }^{12}$. Besides the known metabolic risk profile associated with the use of immunosuppressive medication, several in vitro studies have provided evidence for a prohemostatic effect of such drugs ${ }^{14,15}$.

While there is laboratory evidence for a hypercoagulable state during and directly after OLT, it is unclear whether the hypercoagulability persists and, if so, for how long. To our knowledge there has been no study investigating the hemostatic potential in liver transplant recipients long after a successful transplant. We aimed to investigate the long-term status of the hemostatic system by various assays of hemostatic competence in patients one year after OLT. Understanding the hemostatic state of transplanted patients is essential for clinical practice and for the development of preventive measures for short- and long term vascular complications.

\section{Methods}

\section{Patients}

We designed a prospective cohort study. Fifteen adult patients who visited the outpatient Hepatology Clinic of the University Medical Center Groningen (UMCG) in The Netherlands for their one-year follow-up visit after OLT, and had adequate liver function as assessed by routine laboratory parameters such as aspartate aminotransferase (ASAT) and alanine aminotransferase (ALAT), bilirubin, albumin, and PT, were included in this study. The control group consisted of 30 healthy volunteers from our laboratory staff. Patients and controls with a history of thrombotic complications, congenital coagulation disorders, active graft rejection, active infection, or who had used anticoagulant drugs in the past 10 days, suffered from disease recurrence, or were pregnant were excluded. A brief questionnaire was used to collect demographic and disease information (Supplementary File 1).

\section{Plasma samples}

Blood samples were drawn by veni-puncture and collected into vacuum tubes containing $3.8 \%$ trisodium citrate as an anticoagulant (Becton Dickinson, Breda, The Netherlands), at a blood to anticoagulant ratio of 9:1. Platelet-poor plasma was prepared by double centrifugation at $2000 \mathrm{~g}$ and $10.000 \mathrm{~g}$ respectively for $10 \mathrm{~min}$. Plasma was snap-frozen and stored at $-80^{\circ} \mathrm{C}$ until use.

\section{Primary hemostasis}

Plasma levels of VWF were determined with an in-house enzymelinked immunosorbent assay (ELISA) using commercially available polyclonal antibodies (A0082 for coating and P0226 for detection, both are rabbit anti-human antibodies, P0226 is a horseradishperoxidase conjugated version of A0082 (RRID:AB_579516), DAKO, Glostrup, Denmark). A disintegrin and metalloproteinase with a thrombospondin type 1 motif, member 13 (ADAMTS13) activity was measured in plasma which was pretreated for 30 minutes at $37^{\circ} \mathrm{C}$ with bilirubin oxidase $(10 \mathrm{U} / \mathrm{mL}$; Sigma-Aldrich, Zwijndrecht, The Netherlands) to avoid interference of bilirubin with the assay. ADAMTS13 activity was assessed using the FRETS-VWF73 assay (Peptanova, Sandhausen, Germany) based on method described by Kokame et al. ${ }^{16}$. The antigen levels of VWF and the activity of ADAMTS13 in pooled normal plasma were set at $100 \%$, and values obtained in test plasmas were expressed as a percentage of pooled normal plasma.

Platelet activation was assessed by measuring plasma levels of soluble P-selectin and platelet factor 4 (PF4) with a commercially available ELISAs (R\&D Systems, Abingdon, United Kingdom).

\section{Thrombin generation}

The thrombin generation test was performed using platelet-poor plasma (PPP) with the fluorimetric method described by Hemker, Calibrated Automated Thrombography ${ }^{\otimes}(\mathrm{CAT})^{17}$. Coagulation was activated using a commercial trigger composed of recombinant tissue factor (TF) at a concentration of $4 \mathrm{pM}$ and phospholipids at a 
concentration of $4 \mu \mathrm{M}$, in the presence or absence of soluble thrombomodulin (TM) (Thrombinoscope BV, Maastricht, The Netherlands). Thrombin Calibrator (Thrombinoscope BV, Maastricht, The Netherlands) was added to the wells containing plasma to calibrate the thrombin generation curves. A fluorogenic substrate with $\mathrm{CaCl}_{2}$ (FluCa-kit, Thrombinoscope BV, Maastricht, The Netherlands) was dispensed in each well to allow a continuous registration of thrombin generation. Fluorescence produced was read every 20 seconds by a fluorometer, Fluoroskan Ascent ${ }^{\circledR}$ (ThermoFisher Scientific, Helsinki, Finland). All experiments were performed in triplicate.

The endogenous thrombin potential (ETP), peak height, velocity index and lag time were derived from the thrombin generation curves by the Thrombinoscope software.

Level of prothrombin $\mathrm{F} 1+2$ fragment in plasma were determined with a commercially available ELISA (Siemens, Breda, The Netherlands) according to the manufacturer's instructions.

\section{Routine coagulation laboratory tests}

Levels of factor (F) VIII, II, antithrombin (AT) and Protein C were measured on an automated coagulation analyzer (ACL 300 TOP) with reagents and protocols from the manufacturer (Recombiplastin 2G and FII depleted plasma for FII, Hemosil (R) SynthASil and FVIII depleted plasma for FVIII, Liquid Antithrombin reagent for AT, and Hemosil Protein C for Protein C measurements; Instrumentation Laboratory, Breda, the Netherlands).

Plasma levels of Tissue Factor Pathway Inhibitor (TFPI) were determined with an in-house ELISA as previously described ${ }^{18}$.

\section{Fibrinolytic potential}

Fibrinolytic potential was assessed using a plasma-based clot lysis assay. Lysis of a tissue factor-induced clot by exogenous tissue plasminogen activator (tPA) was studied by monitoring changes in turbidity during clot formation and subsequent lysis as described previously ${ }^{19}$. In short, $50 \mu \mathrm{L}$ plasma was pipetted in a 96-well microtiter plate. Subsequently, a mixture containing phospholipid vesicles, $\mathrm{tPA}$, tissue factor, and $\mathrm{CaCl}_{2}$, adjusted to a total volume of $50 \mu \mathrm{L}$ by addition of HEPES (N-2-hydroxytethylpiperazine$\mathrm{N}$-2-ethanesulfonic acid) buffer (25 mM HEPES, $137 \mathrm{mM} \mathrm{NaCl}$, $3.5 \mathrm{mM} \mathrm{KCl}, 3 \mathrm{mM} \mathrm{CaCl}_{2}, 0.1 \%$ bovine serum albumin, $\mathrm{pH} 7.4$ ) was added using a multichannel pipette. In a kinetic microplate reader (Versamax, Molecular Devices, Sunnyvale, CA), the optical density at $405 \mathrm{~nm}$ was monitored every 20 seconds at $37^{\circ} \mathrm{C}$, resulting in a clot-lysis turbidity profile. Clot lysis times were derived from the clot-lysis turbidity profiles using in house-generated software. The clot lysis time was defined as the time from the midpoint of the clear to maximum turbid transition, representing clot formation, to the midpoint of the maximum turbid to clear transition, representing the lysis of the clot.

Plasma levels of plasminogen activator inhibitor-1 (PAI-1) levels were determined with a commercially available ELISA (Sekisui, Stamford, USA).

\section{Statistical analyses}

Data are expressed as means (with standard deviations (SDs)), medians (with interquartile ranges), or numbers (with percentages) as appropriate. Means of two groups were compared by Student's t-test or Mann-Whitney U test as appropriate. Spearman's correlation coefficient was used to assess correlation between continuous variables. P values of 0.05 or less were considered statistically significant. GraphPad Prism (San Diego, USA) and IBM SPSS Statistics 20 (New York, USA) were used for analyses.

\section{Ethics statement}

Written informed consent was obtained from every participant in this study. The study was approved by the local Medical Ethics Committee from the University Medical Center of Groningen (protocol number 2012.098). Study procedures were in accordance with the Helsinki Declaration of 1975.

\section{Results}

\section{Patient characteristics}

All of the patients included in this study underwent OLT between 2011 and 2012. All patients received a full-size graft. None of the patients suffered from thrombosis prior to OLT or had postoperative thrombotic complications within the first year. Five patients suffered from diabetes mellitus at time of the blood draw, and four of these were insulin-dependent. Two of these patients had developed diabetes after OLT. There were five patients that were on platelet aggregation inhibitors (calcium carbasalate or aspirin) at the time of the blood draw. Two of these patients had coronary disease for which they had undergone coronary interventions prior to OLT. One patient had left ventricular hypertrophy and one patient had paroxysmal atrial fibrillation. The fifth patient appeared to have fragile arteries at the anastomotic site during OLT for which postoperative aspirin was started. Two patients suffered from hypertension, and two patients smoked cigarettes. Patient and background characteristics are presented in Table 1.

\section{A dysbalanced VWF/ADAMTS13 ratio in liver transplant recipients}

Patients had significantly higher plasma levels of the plateletadhesive protein VWF compared to healthy controls (253\% (200323) (median (IQR)) vs. 99\% (63-114), respectively, Figure 1A). The activity of ADAMTS13, the VWF-cleaving protease was comparable between patients and controls (82\% (75-118) vs. 94\% (85102) respectively, Figure 1B). Plasma levels of sP-selectin were significantly elevated in patients compared to controls $(28.0 \mathrm{pmol} / \mathrm{L}$ (25.0-39.0) vs. 21.0 pmol/L (18.8-25.3) respectively, Figure 1C). Levels of sP-selectin were similar in patients that were on calcium carbasalate or ascal compared to those who were not $(33.0 \mathrm{pmol} / \mathrm{L}$ (20.0-41.0) vs. $28.0 \mathrm{pmol} / \mathrm{L}$ (25.0-33.0) respectively; $\mathrm{p}=0.68)$. However, levels of PF4 were similar among patients and controls (595 ng/ml (369-912) vs. 634 ng/ml (496-786) respectively; Figure 1D).

\section{Decreased in vitro thrombin generation is associated} with elevated plasma levels of TFPI and AT, but not with differences in in vivo thrombin generation in liver transplant recipients

Thrombin generation assays showed that patients had a decreased procoagulant capacity, both in presence and absence of thrombomodulin (Figure 2). Specifically, patients had a decreased ETP compared to controls, both in presence and absence of thrombomodulin (344 nM IIa×min (284-414) vs. $492 \mathrm{nM}$ IIa×min (385-693) respectively in presence of thrombomodulin). Patients 


\begin{tabular}{|c|c|c|}
\hline Mean age (years) $( \pm \mathrm{SD})$ & & $50.0( \pm 1.9)$ \\
\hline Male/female ratio & & $11 / 4$ \\
\hline Mean BMI $( \pm \mathrm{SD})$ & & $26.0( \pm 2.9)$ \\
\hline \multirow[t]{8}{*}{ Etiology of liver disease (no of patients) } & Biliary cirrhosis & 5 \\
\hline & Alcoholic cirrhosis & 2 \\
\hline & Viral cirrhosis & 3 \\
\hline & Acute liver failure & 1 \\
\hline & Familial amyloidotic polyneuropathy & 1 \\
\hline & Morbus Wilson & 1 \\
\hline & Alcoholic cirrhosis and NASH & 1 \\
\hline & $\mathrm{NASH}$ & 1 \\
\hline Piggyback/conventional implantation & & $12 / 3$ \\
\hline \multirow[t]{3}{*}{ Donor type } & Heartbeating & 10 \\
\hline & Non-heartbeating & 4 \\
\hline & Domino & 1 \\
\hline \multirow[t]{4}{*}{ Immunosuppressive regimen (no of patients) } & Calcineurin inhibitor & 2 \\
\hline & Calcineurin inhibitor + steroid & 1 \\
\hline & Calcineurin inhibitor + steroid + purine antagonist & 10 \\
\hline & Calcineurin inhibitor + purine antagonist & 2 \\
\hline \multirow[t]{8}{*}{ Other medication (no of patients) } & Aspirin & 5 \\
\hline & Insulin & 4 \\
\hline & Metformin & 2 \\
\hline & Calcium antagonist & 4 \\
\hline & ACE-inhibitors & 4 \\
\hline & Betablocker & 1 \\
\hline & Diuretic & 1 \\
\hline & Proton pump inhibitor & 13 \\
\hline \multirow[t]{8}{*}{ Laboratory assessment (medians and IQR) } & Hemoglobin (mmol/L) & $8.6(8.2-9.0)$ \\
\hline & Platelets $\left(\times 10^{9} / \mathrm{L}\right)$ & $160(136-192)$ \\
\hline & Total bilirubin $(\mu \mathrm{mol} / \mathrm{L})$ & $9.0(6.0-11.0)$ \\
\hline & ASAT (U/L) & $26(18-3)$ \\
\hline & ALAT (U/L) & $25(20-38)$ \\
\hline & Albumin (g/L) & $45(44-47)$ \\
\hline & INR & $1.1(1.0-1.1)$ \\
\hline & Creatinine $(\mu \mathrm{mol} / \mathrm{L})$ & $77(72-107)$ \\
\hline
\end{tabular}

*To convert values for hemoglobin to $\mathrm{g} / \mathrm{dl}$, multiply by 1.650. To convert values for bilirubin to $\mathrm{mg} / \mathrm{dl}$ divide by 88.4 .

also had a decreased peak height and velocity index, and a prolonged lagtime compared to controls (Table 2).

The ETP ratio, an index of the anticoagulant capacity of the protein $\mathrm{C}$ system defined as the ratio of the ETP with-to-without TM, was significantly lower in patients compared to controls (Table 2).

Plasma levels of FII were similar in patients and controls $(99 \%$ (94-111) vs. 106\% (96-117) respectively, Figure 3A). Levels of FVIII on the other hand were significantly higher in patients compared to controls (122\% (111-153) vs. 87\% (74-109) respectively, Figure 3B).
Plasma levels of TFPI were significantly higher in patients compared to controls (184\% (147-204) vs. 127\% (82-148) respectively, Figure 4A). There was no difference in protein $\mathrm{C}$ levels between the groups (107\% (87-124) vs. 104\% (95-126) respectively, Figure 4B). In the patient group protein $\mathrm{C}$ correlated inversely with ETP in presence of TM (Figure 4C). Levels of AT were slightly, but significantly higher in patients compared to controls (114\% (99-134) vs. 104\% (97-113) respectively, Figure 4D).

Plasma levels of prothrombin fragment 1+2, an indicator of in vivo thrombin generation, were similar between patients and controls (216 pmol/L (146-260) vs. 178 pmol/L (136-210) respectively, Figure 5). 

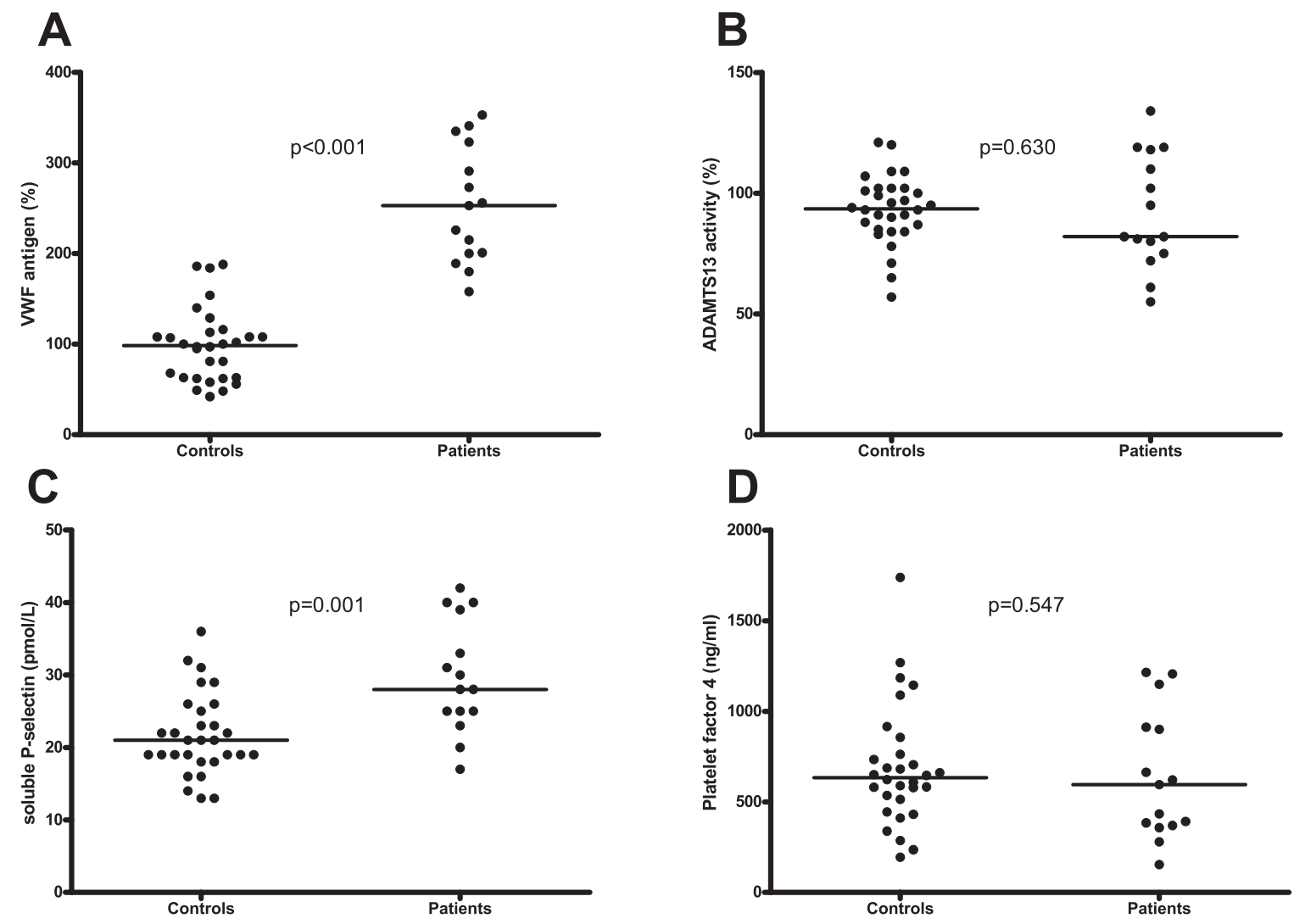

Figure 1. VWF and Platelet parameters in healthy controls and patients. A. Plasma levels of von Willebrand factor (VWF) in patients and healthy controls. B. ADAMTS13 activity in plasma from patients and healthy controls. C. Plasma levels of soluble P-selectin in patients and controls. D. Plasma levels of Platelet Factor 4 in patients and controls. Horizontal bars indicate medians.

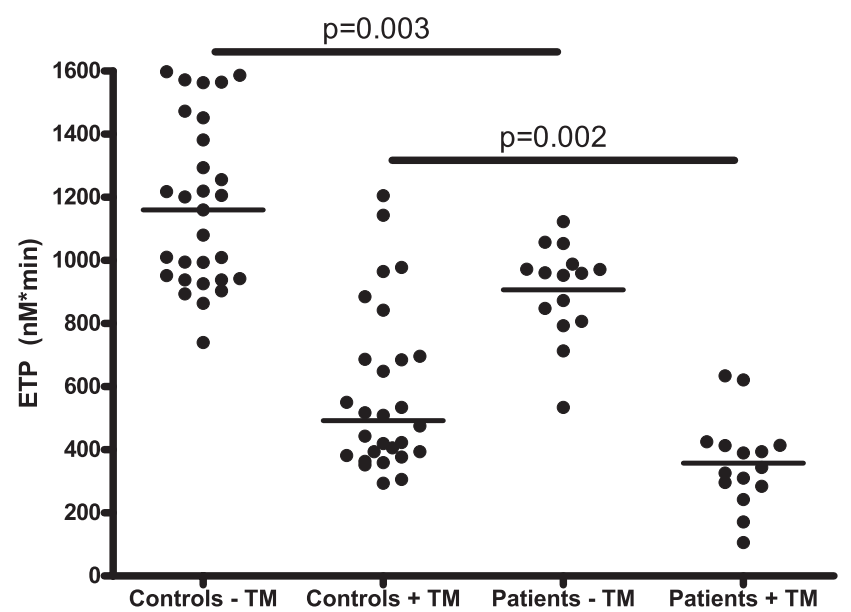

Figure 2. Endogenous Thrombin Potential (ETP) in plasma from patients and healthy controls in absence and presence of thrombomodulin (TM). Horizontal bars indicate medians.

Decreased plasma fibrinolytic potential associated with elevated plasma levels of PAl-1 in liver transplant recipients Clot lysis times were significantly prolonged in patients compared to controls (66.8 $\mathrm{min}(61.3-75.1)$ vs. $54.2 \mathrm{~min}$ (50.1-60.8) respectively Figure 6A and B). Plasma levels of PAI-1 were significantly higher in patients compared to controls $(8.2 \mathrm{ng} / \mathrm{ml}(4.5-11.8) \mathrm{vs}$. $2.1 \mathrm{ng} / \mathrm{ml}(2.6-5.4)$ respectively) and correlated with clot lysis time (Figure 6C and D).

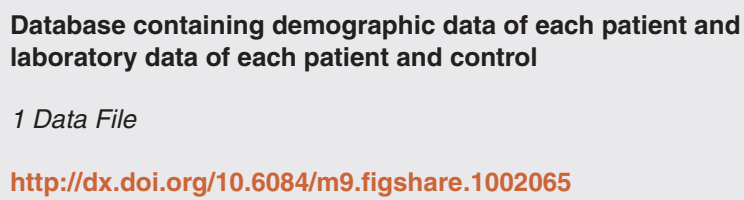

\section{Discussion}

The main finding of this study is that one year after OLT patients with a well- functioning graft are in a hypercoagulable state. This hypercoagulable state is caused by elevated plasma levels of VWF (resulting in a hyperactive primary hemostatic system), and a hypofibrinolytic state due to elevated plasma levels of PAI-1. Nevertheless, thrombin generation was decreased in patients on year after OLT, which was related to increased levels of TFPI and AT. This decreased thrombin generation may, in part, compensate for the hypercoagulable changes. High VWF and decreased plasma fibrinolytic potential, however, are established risk factors for venous and arterial thrombosis, and we therefore speculate that the unbalanced hemostasis in patients one year after OLT may contribute to their increased risk for thrombotic events. The observed increased levels of VWF, sP-selectin, FVIII, TFPI, and PAI-1, in patients one year 
Table 2. Parameters derived from thrombin generation curves generated in absence and presence of TM. Data are presented as medians with interquartile range.

\begin{tabular}{|llll}
\hline & Patients & Controls & p-value \\
\hline ETP ratio & $0.4(0.3-0.4)$ & $0.5(0.3-0.8)$ & 0.037 \\
\hline Velocity index TM- (nM Ila/min) & $55.0(43.0-67.0)$ & $73.0(56.0-134.0)$ & 0.004 \\
\hline Velocity index TM+ (nM IIa/min) & $43.0(34.0-54.0)$ & $58.5(46.8-93.8)$ & 0.002 \\
\hline Peak TM- (nM Ila) & $172.0(162.0-196.0)$ & $190.0(182.0-306.0)$ & 0.004 \\
\hline Peak TM+ (nM Ila) & $98.0(78.0-98.0)$ & $134.0(100.0-187.0)$ & 0.003 \\
\hline Lag time TM- $(\mathrm{min})$ & $2.7(2.3-2.7)$ & $2.0(1.7-2.0)$ & $<0.001$ \\
\hline Lag time TM+ $(\mathrm{min})$ & $2.3(2.0-2.5)$ & $1.7(1.7-2.0)$ & $<0.001$ \\
\hline
\end{tabular}
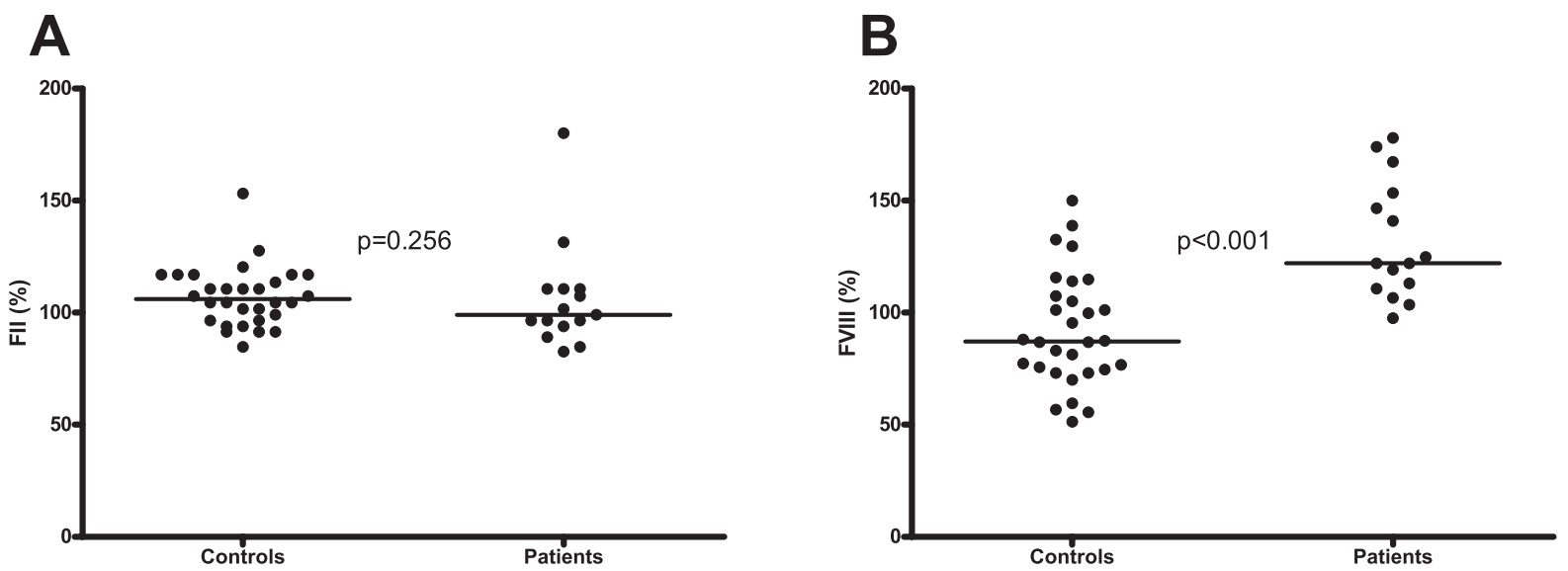

Figure 3. Coagulation factor levels in patients and healthy controls. A. Plasma levels of factor II in patients and healthy controls. B. Factor VIII plasma levels in patients and healthy controls. Horizontal bars indicate medians.

after OLT, are likely the result of chronic endothelial injury. All of these coagulation proteins are produced by endothelial cells. It has been demonstrated that the use of immunosuppressive drugs leads to endothelial cell activation and release of $\mathrm{VWF}^{14,20-25}$. Also, an inhibitory effect of immunosuppressive medication on fibrinolysis has been demonstrated, as evidenced by elevated levels of PAI- ${ }^{25-27}$

It thus appears plausible that the elevation in levels of VWF, sP-selectin, FVIII, TFPI, and PAI-1, which explain the majority of the hemostatic unbalance at one year after OLT, is related to immunosuppression. Nevertheless, other causes for endothelial activation such as (de novo) diabetes, smoking, and infection or a proinflammatory status may also contribute to endothelial cell activation. Of note, none of the other drugs used by some of the patients, such as proton pump inhibitors, blood-glucose lowering medication or calcium antagonists are known to cause endothelial cell activation.

Previously we have summarized clinical and laboratory evidence for hypercoagulability as a contributor to thrombotic complications after liver transplantation ${ }^{11}$. Several of the hemostatic abnormalities that we have described in the present study have been linked to clinical thrombotic events in non-transplant patients and, therefore, are in line with our previously formulated hypotheses. Increased levels of VWF and FVIII have been (independently and in combination) described as a risk factor for venous thromboembolism but also for thromboembolic cardio- and cerebrovascular disease and mortality in several studies ${ }^{28-31}$. Hypofibrinolysis, as defined by prolonged plasma-based clot lysis times or by increased plasma levels of PAI-1 have been associated with a risk for venous thrombosis and thromboembolic cardiovascular disease $\mathrm{e}^{32-36}$.

With increasing long term survival after OLT, thromboembolic cardio- and cerebrovascular disease has become an increasingly threatening factor for OLT recipients, warranting preventative measures ${ }^{11}$. While there are no laboratory studies investigating the hemostatic status of patients 5-10 years after their OLT, it is plausible that the hemostatic abnormalities induced by immunosuppressive drugs described in this study persist or even aggravate over time. The findings of this study may point to the necessity of antihemostatic treatment to prevent cardiovascular disease after OLT. While both sP-selectin and PF4 are considered markers of platelet activation, only PF4 is solely released by activated platelets. 

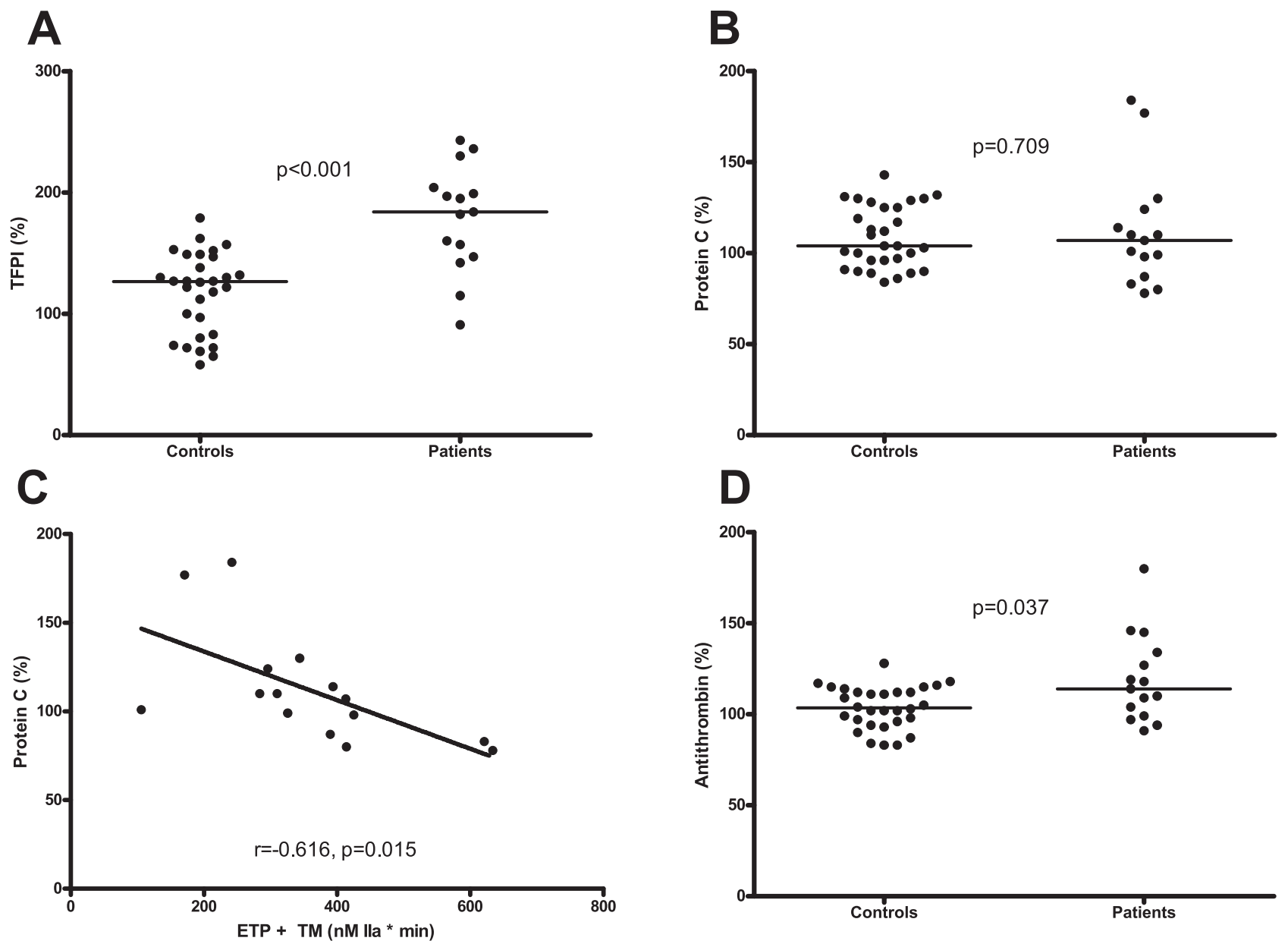

Figure 4. Coagulation factor levels in patients and healthy controls. A. Plasma levels of TFPI in patients and healthy controls. B. Protein $\mathrm{C}$ levels in plasma from patients and healthy controls. C. Correlation between the Endogenous Thrombin Potential (ETP) measured in the presence of thrombomodulin (TM) and plasma levels of protein C in patients. D. Antithrombin (AT) levels in plasma from patients and healthy controls. Horizontal bars indicate medians.

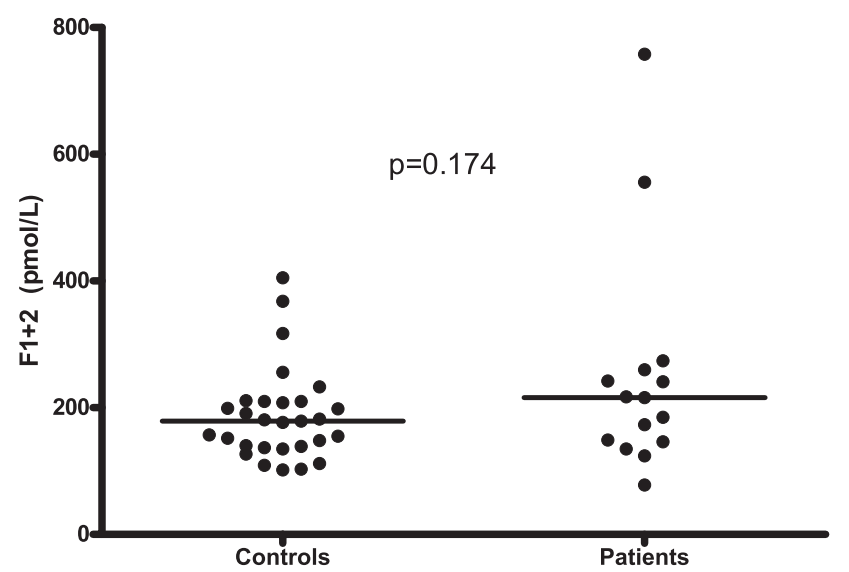

Figure 5. Plasma levels of prothrombin fragment $1+2$ in patients and healthy controls. Horizontal bars indicate medians.
P-selectin is present in both endothelial cells as well as platelets, and a soluble fragment is released upon activation of these cells. The fact that only levels of sP-selectin were elevated in liver transplant recipients while levels of PF4 were similar to controls doesn't indicate an increased platelet activity but rather increased endothelial cell activation. However, the elevated levels of VWF may lead thromboembolic events, which may be prevented by anti-platelet therapy. It has been demonstrated in a single retrospective study that long-term administration of aspirin lowers the incidence of HAT after OLT without increasing bleeding events ${ }^{37}$. Platelet inhibition after OLT by aspirin might not only decrease the risk for HAT but also the risk for thromboembolic cardiovascular disease similar to that in the general population, although this has not been assessed in clinical studies.

The results of our study suggest that the hemostatic imbalance of liver transplant recipients is not due to transplant-related effects, 

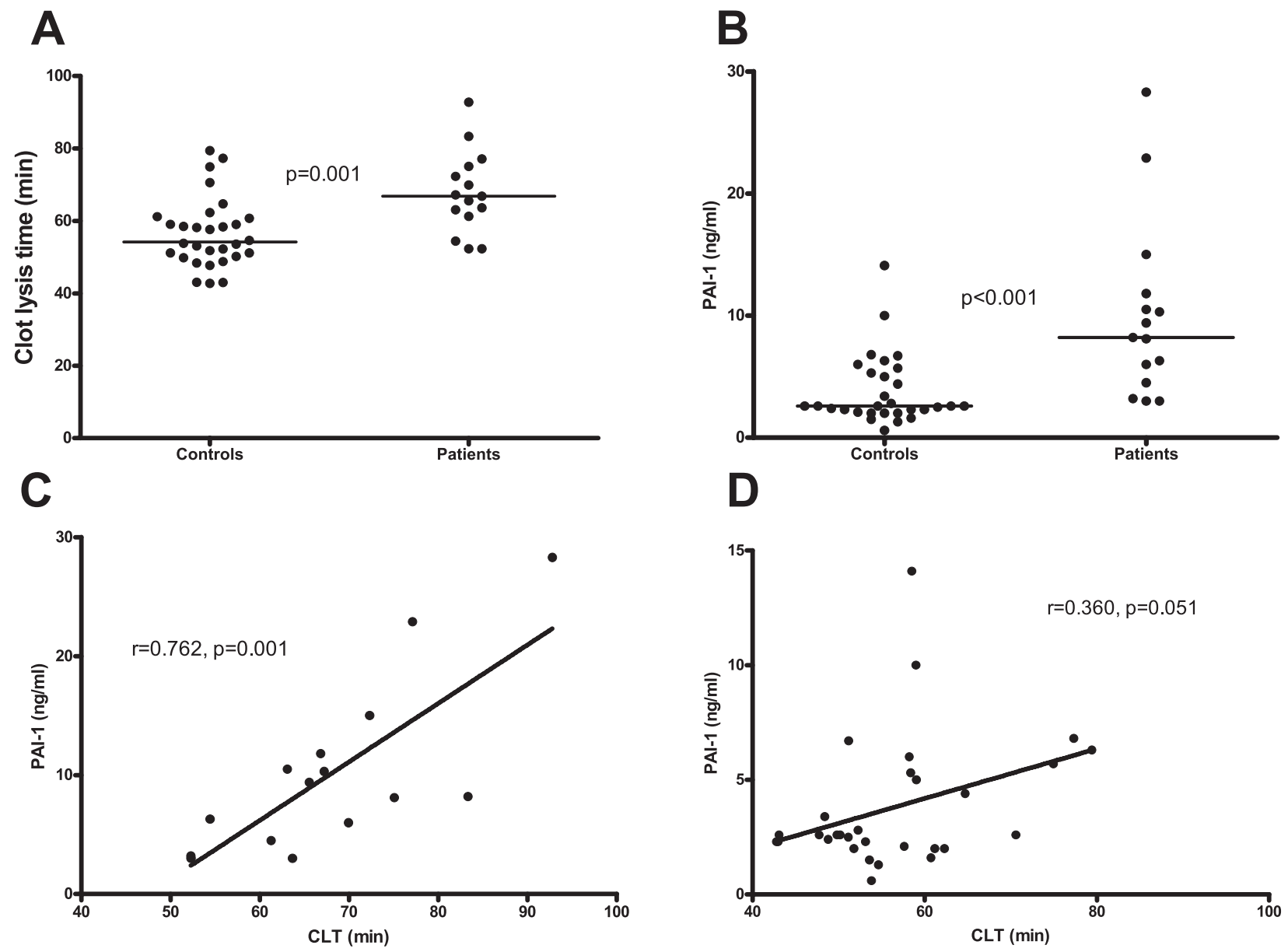

Figure 6. Fibrinolytic status in patients and healthy controls. A. Clot lysis time assessed in plasma from patients and healthy controls B. Plasma levels of PAI-1in patients and healthy controls. C. Correlation between clot lysis times and PAI-1 plasma levels in patients and D. controls. Horizontal bars in panels A and B indicate medians.

but to the endothelial activating properties of immunosuppression. Our results therefore may be likely extended to other forms of solid organ transplantation. Indeed, kidney transplant recipients are also at risk for thrombotic events, which may also in part be related to dysregulated hemostasis ${ }^{38-41}$. Although antihemostatic therapy may be beneficial, partial or complete withdrawal of immune suppression may be an optimal strategy to avoid post transplant thrombotic complication.

In conclusion, one year after liver transplantation liver transplant recipients display dysregulated hemostasis which appears to be related to endothelial activation. Whereas elevated levels of VWF and decreased fibrinolytic capacity may be related to thrombotic complications in liver transplant recipients, this risk may be attenuated in part by decreased thrombin generating capacity.

\section{Data availability}

figshare: Database containing demographic data of each patient and laboratory data of each patient and control. Doi: 10.6084/ m9.figshare. $1002065^{42}$

\section{Informed consent}

Written informed consent was obtained from participant in this study.

\section{Author contributions}

TL: designed research, interpreted data, and drafted manuscript. FA: responsible for patient inclusion, interpreted data and drafted manuscript. JA: carried out laboratory measurements. $\mathrm{HB}$ and AvdB: responsible for patient inclusion, interpreted data. RJP: designed research, interpreted data. All authors were involved in revision of the draft manuscript and have agreed to the final content.

\section{Competing interests}

No competing interests were disclosed.

\section{Grant information}

The author(s) declared that no grants were involved in supporting this work. 
1. Lisman T, Porte RJ: Rebalanced hemostasis in patients with liver disease: evidence and clinical consequences. Blood. 2010; 116(6): 878-85. PubMed Abstract | Publisher Full Text

2. Lisman T, Bakhtiari K, Pereboom IT, et al:: Normal to increased thrombin generation in patients undergoing liver transplantation despite prolonged conventiona coagulation tests. $J$ Hepatol. 2010; 52(3): 355-61. PubMed Abstract | Publisher Full Text

3. Tripodi A, Salerno F, Chantarangkul V, et al:: Evidence of normal thrombin generation in cirrhosis despite abnormal conventional coagulation tests. Hepatology. 2005; 41(3): 553-8.

PubMed Abstract | Publisher Full Text

4. Senzolo M, Sartori MT, Lisman T: Should we give thromboprophylaxis to patients with liver cirrhosis and coagulopathy? HPB (Oxford). 2009; 11(6): 459-64. PubMed Abstract | Publisher Full Text | Free Full Text

5. Sogaard KK, Horvath-Puho E, Gronbaek H, et al:: Risk of venous thromboembolism in patients with liver disease: a nationwide population-based case-control study. Am J Gastroenterol. 2009; 104(1): 96-101. PubMed Abstract | Publisher Full Text

6. Gulley D, Teal E, Suvannasankha A, et al.: Deep vein thrombosis and pulmonary embolism in cirrhosis patients. Dig Dis Sci. 2008; 53(11): 3012-7. PubMed Abstract | Publisher Full Text

7. Northup PG, McMahon MM, Ruhl AP, et al.: Coagulopathy does not fully protect hospitalized cirrhosis patients from peripheral venous thromboembolism. Am J Gastroenterol. 2006; 101(7): 1524-8. PubMed Abstract | Publisher Full Text

8. Garca-Fuster MJ, Abdilla N, Fabi MJ, et al.: [Venous thromboembolism and liver cirrhosis]. Rev Esp Enferm Dig. 2008; 100(5): 259-262. PubMed Abstract

9. Pereboom IT, Adelmeijer J, van Leeuwen Y, et al:: Development of a severe von Willebrand factor/ADAMTS13 dysbalance during orthotopic liver transplantation. Am J Transplant. 2009; 9(5): 1189-96. PubMed Abstract | Publisher Full Text

10. Lisman T, Leebeek FW, Meijer K, et al:: Recombinant factor VIla improves clot formation but not fibrolytic potential in patients with cirrhosis and during liver transplantation. Hepatology. 2002; 35(3): 616-21. PubMed Abstract | Publisher Full Text

11. Arshad F, Lisman T, Porte RJ: Hypercoagulability as a contributor to thrombotic complications in the liver transplant recipient. Liver Int. 2013; 33(6): 820-7. PubMed Abstract | Publisher Full Text

12. Duffy JP, Hong JC, Farmer DG, et al.: Vascular complications of orthotopic liver transplantation: experience in more than 4,200 patients. $J$ Am Coll Surg. 2009; 208(5): 896-903, discussion 903-5. PubMed Abstract | Publisher Full Text

13. Borg MA, van der Wouden EJ, Sluiter WJ, et al.: Vascular events after liver transplantation: a long-term follow-up study. Transpl Int. 2008; 21(1): 74-80. PubMed Abstract | Publisher Full Text

14. Huang LQ, Whitworth JA, Chesterman CN: Effects of cyclosporin A and dexamethasone on haemostatic and vasoactive functions of vascula endothelial cells. Blood Coagul Fibrinolysis. 1995; 6(5): 438-45. PubMed Abstract | Publisher Full Tex

15. Bombeli T, Müller M, Straub PW, et al:: Cyclosporine-induced detachment of vascular endothelial cells initiates the intrinsic coagulation system in plasma and whole blood. J Lab Clin Med. 1996; 127(6): 621-34. PubMed Abstract | Publisher Full Text

16. Kokame K, Nobe $Y$, Kokubo T, et al.: FRETS-VWF73, a first fluorogenic substrate for ADAMTS13 assay. Br J Haematol. 2005; 129(1): 93-100. PubMed Abstract | Publisher Full Text

17. Ruitenbeek K, Meijers JC, Adelmeijer J, et al:: Intact thrombomodulin-mediated regulation of fibrinolysis during and after liver transplantation, despite a profoundly defective thrombomodulin-mediated regulation of coagulation. J Thromb Haemost. 2010; 8(7): 1646-9. PubMed Abstract | Publisher Full Text

18. Maurissen LF, Castoldi E, Simioni $P$, et al:: Thrombin generation-based assays to measure the activity of the TFPI-protein S pathway in plasma from normal and protein S-deficient individuals. J Thromb Haemost. 2010; 8(4): 750-8. PubMed Abstract | Publisher Full Text

19. Lisman T, de Groot PG, Meijers JC, et al.: Reduced plasma fibrinolytic potential is a risk factor for venous thrombosis. Blood. 2005; 105(3): 1102-5. PubMed Abstract | Publisher Full Text

20. Jeanmart $\mathrm{H}$, Malo $\mathrm{O}$, Carrier $\mathrm{M}$, et al.: Comparative study of cyclosporine and tacrolimus vs newer immunosuppressants mycophenolate mofetil and rapamycin on coronary endothelial function. J Heart Lung Transplant. 2002; 21(9): 990-8.

PubMed Abstract | Publisher Full Text

21. Weis M, Wildhirt SM, Schulze C, et al:: Impact of immunosuppression on coronary endothelial function after cardiac transplantation. Transplant Proc. 1998; 30(3): $871-2$

PubMed Abstract

22. Ovuworie CA, Fox ER, Chow CM, et al: Vascular endothelial function in cyclosporine and tacrolimus treated renal transplant recipients. Transplantation. 2001; 72(8): 1385-8.

PubMed Abstract | Publisher Full Text

23. Schrama YC, van Dam T, Fijnheer R, et al.: Cyclosporine is associated with endothelial dysfunction but not with platelet activation in renal transplantation. Neth J Med. 2001; 59(1): 6-15.

PubMed Abstract | Publisher Full Text

24. Morris ST, McMurray JJ, Rodger RS, et al:: Endothelial dysfunction in renal transplant recipients maintained on cyclosporine. Kidney Int. 2000; $\mathbf{5 7 ( 3 )}$ 1100-6.

PubMed Abstract | Publisher Full Text

25. Baas MC, Gerdes VE, Ten Berge IJ, et al:: Treatment with everolimus is associated with a procoagulant state. Thromb Res. 2013; 132(2): 307-11. PubMed Abstract | Publisher Full Text

26. Patrassi GM, Sartori MT, Rigotti P, et al: Reduced fibrinolytic potential one yea after kidney transplantation. Relationship to long-term steroid treatment. Transplantation. 1995; 59(10): 1416-20. PubMed Abstract

27. Levi M, Wilmink J, Büller HR, et al:: Impaired fibrinolysis in cyclosporine-treated renal transplant patients. Analysis of the defect and beneficial effect of fish-oil. Transplantation. 1992; 54(6): 978-83. PubMed Abstract

28. Tsai AW, Cushman M, Rosamond WD, et al:: Coagulation factors, inflammation markers, and venous thromboembolism: the longitudinal investigation of thromboembolism etiology (LITE). Am J Med. 2002; 113(8): 636-42. PubMed Abstract | Publisher Full Text

29. Martinelli I: von Willebrand factor and factor VIII as risk factors for arterial and venous thrombosis. Semin Hematol. 2005; 42(1): 49-55. PubMed Abstract | Publisher Full Text

30. Folsom AR, Rosamond WD, Shahar E, et al.: Prospective study of markers of hemostatic function with risk of ischemic stroke. The Atherosclerosis Risk in Communities (ARIC) Study Investigators. Circulation. 1999; 100(7): 736-42. PubMed Abstract | Publisher Full Text

31. Jansson JH, Nilsson TK, Johnson O: von Willebrand factor, tissue plasminogen activator, and dehydroepiandrosterone sulphate predict cardiovascular death in a 10 year follow up of survivors of acute myocardial infarction. Heart. 1998; 80(4): 334-7.

PubMed Abstract | Publisher Full Text | Free Full Text

32. Almér LO, Ohlin H: Elevated levels of the rapid inhibitor of plasminogen activator (t-PAI) in acute myocardial infarction. Thromb Res. 1987; 47(3): 335-9.

PubMed Abstract | Publisher Full Text

33. Meltzer ME, Lisman T, de Groot PG, et al.: Venous thrombosis risk associated with plasma hypofibrinolysis is explained by elevated plasma levels of TAFI and PAI-1. Blood. 2010; 116(1): 113-21.

PubMed Abstract | Publisher Full Text

34. Meltzer ME, Lisman T, Doggen CJ, et al:: Synergistic effects of hypofibrinolysis and genetic and acquired risk factors on the risk of a first venous thrombosis. PLOS Med. 2008; 5(5): e97.

PubMed Abstract | Publisher Full Text | Free Full Text

35. Hamsten A, Wiman B, de Faire $U$, et al:: Increased plasma levels of a rapid inhibitor of tissue plasminogen activator in young survivors of myocardial infarction. N Engl J Med. 1985; 313(25): 1557-63. PubMed Abstract | Publisher Full Text

36. Reddel CJ, Curnow JL, Voitl J, et al.: Detection of hypofibrinolysis in stable coronary artery disease using the overall haemostatic potential assay. Thromb Res. 2013; 131(5): 457-62.

PubMed Abstract | Publisher Full Text

37. Vivarelli M, La Barba G, Cucchetti A, et al:: Can antiplatelet prophylaxis reduce the incidence of hepatic artery thrombosis after liver transplantation? Liver Transpl. 2007; 13(5): 651-4.

PubMed Abstract | Publisher Full Text

38. Irish $\mathrm{AB}$, Green FR: Environmental and genetic determinants of the hypercoagulable state and cardiovascular disease in renal transplant recipients. Nephro Dial Transplant. 1997; 12(1): 167-73. PubMed Abstract | Publisher Full Text

39. Allen RD, Michie CA, Murie JA, et al: Deep venous thrombosis after renal transplantation. Surg Gynecol Obstet. 1987; 164(2): 137-42. PubMed Abstract

40. Humar A, Johnson EM, Gillingham KJ, et al:: Venous thromboembolic complications after kidney and kidney-pancreas transplantation: a multivariate analysis. Transplantation. 1998; 65(2): 229-34. PubMed Abstract

41. The 12th Report of the Human Renal Transplant Registry. Prepared by the Advisory Committee to the Renal Transplant Registry. JAMA. 1975; 233(7): 787-96.

PubMed Abstract | Publisher Full Text

42. Arshad F, Adelmeijer J, Blokzijl $\mathrm{H}$, et al.: Database containing demographic data of each patient and laboratory data of each patient and control. Figshare. 2014. Data Source 


\title{
Open Peer Review
}

\section{Current Peer Review Status:}

\section{Version 1}

Reviewer Report 04 July 2014

https://doi.org/10.5256/f1000research.4265.r5188

(C) 2014 Gatt A. This is an open access peer review report distributed under the terms of the Creative Commons Attribution License, which permits unrestricted use, distribution, and reproduction in any medium, provided the original work is properly cited.

\begin{abstract}
Alex Gatt
Haematology Department, Mater Dei Hospital, Msida, Malta

Arshad et al. present an interesting study on the haemostatic changes seen 1 year after liver transplantation. This is of particular interest to hepatologists, liver surgeons and haemostasiologists alike. The Groningen group clearly show that these patients, even 1 year after transplantation, still have high FVIII, and VWF. However they do recover their anticoagulant proteins, leading to a brisk reduction of thrombin generation upon the addition of thrombomodulin.

This is a proof of concept study due to the small number of patients. There is a major confounder, as the authors themselves acknowledge in their introduction, which is the chronic immunosuppression which could be leading this 'endothelial activation', but nevertheless whatever the cause it looks likely that this is present and might play a part in the post transplant thrombotic events in these patients.
\end{abstract}

Ideally, the authors should specify what Protein C and AT assays they used, i.e. are they activity assays?

Another confounder is that some patients were on antiplatelet agents and other were not.

It is not clear why the patients still had lower thrombin generation without thrombomodulin. This could be related to the concentration of TF used in the assay.

Were the controls age and sex matched?

Finally, despite the fact that VWF, FVIII and PAI-1 are still elevated 1 year after transplantation, looking at the TG data, the patients seem to be hypocoagulable with lower 
Velocity Index, prolonged LT and lower ETP. There is also a seemingly more profound effect of the natural anticoagulants upon addition of TM. So is this still a case of balanced haemostasis?

Competing Interests: No competing interests were disclosed.

\section{I confirm that I have read this submission and believe that I have an appropriate level of expertise to confirm that it is of an acceptable scientific standard.}

Author Response ( F1000Research Advisory Board Member ) 22 Jul 2014

Ton Lisman, University of Groningen, University Medical Center Groningen, Groningen, The Netherlands

We appreciate the interest of the reviewer in our study and thank him for his constructive comments.

1. The Protein C and AT assays are indeed activity assays using chromogenic substrates. As indicated in the manuscript, these assays were purchased from Instrumentation Laboratory. For a detailed description of the assays see:

http://benelux.instrumentationlaboratory.com/products-services/hemostasisdiagnostics/reagents/thrombophilia.aspx.

2. Although we agree that the use of antiplatelet agents may be a confounder (although antiplatelet agents to our knowledge have not been shown to alter the outcome of most of the assays we have used), we would like to stress that the clinical reality is that liver transplant recipients are frequently prescribed multiple drugs other than immunosuppressants. We were interested to find out whether coagulation abnormalities may contribute to the increased thrombotic risk after liver transplantation. Thus, while acknowledging the fact that the causes of the hemostatic changes observed in liver transplant recipients are likely multicausal (and not fully elucidated by our study), our data show evidence for a hypercoagulable profile in patients one year after transplantation.

3. The reduced thrombin generation in the absence of thrombomodulin is likely due to the elevated levels of TFPI and AT, which have been shown to be key determinants of thrombin generation (J Thromb Haemost. 2008 Jan;6(1):125-31). This reference has been added to the manuscript.

4. Controls were not age and sex matched. We included controls to establish reference values for the various assays performed in the study, similar to how reference values in routine diagnostic laboratories are established. While acknowledging that not all measured variables are constant with age, the differences observed in the endothelial-derived proteins are substantial and not explained by minor changes caused by age. We have altered the text in the materials and methods section to indicate that controls were included only to establish reference ranges, and included age and sex of the controls.

5. We agree that we find evidence of both hyper- and hypocoagulable changes in the 
liver transplant recipients. Our conclusion thus is not that the hemostatic system is in balance, as suggested by the reviewer. Rather, we conclude there is dysregulated hemostasis. The final sentence of the conclusion sums up how we interpret our findings of the study: "Whereas elevated levels of VWF and decreased fibrinolytic capacity may be related to thrombotic complications in liver transplant recipients, this risk may be attenuated in part by decreased thrombin generating capacity."

Competing Interests: No competing interests were disclosed.

Reviewer Report 23 June 2014

https://doi.org/10.5256/f1000research.4265.r5186

(C) 2014 Blasi A. This is an open access peer review report distributed under the terms of the Creative Commons Attribution License, which permits unrestricted use, distribution, and reproduction in any medium, provided the original work is properly cited.

\section{Annabel Blasi}

Hospital Clinic de Barcelona, Barcelona, Spain

In this study, the authors investigated the hemostatic status of liver transplant recipients one year after transplantation, finding a prothrombotic profile based on activated endothelial markers coupled to a hypofibrinolytic state. It point out a very relevant clinical problem as it is the thrombotic complications in the post transplant period. The aim and methods are well defined and well performed, however I would like the authors address some aspects about the study population:

The study population shows several factors which have clearly impact on the endothelial function, apart from immunosuppressive therapy. In order to obtain more information from the data, I suggest that the authors discuss the differences, if any, about the more relevant results: VW, VIII, sP-selectin, TFPI and PAI-1 according to the following sub-groups of patients:

1. Diabetes

2. Cardiovacular disease

3. Etiology of liver disease - Given that a hypercoagulable/hypofibrinolytic state has been suggested in several of the reported etiologies in the study group (biliary cirrhoris, NASH, familial amyloidotic polyneuropathy) those reversibilities after liver transplantation have not been proven.

4. Immunosuppressive regiment.

To discard that some of the aforementioned conditions confers a risk extra for thrombosis.

Otherwise, patients had a decreased ETP compared to controls, both in presence and absence of thrombomodulin. The ETP ratio, an index of the anticoagulant capacity of the protein C system defined as the ratio of the ETP with-to-without thrombomodulin was significantly lower in patients 
compared to controls but interestingly, there was no difference in protein C levels between both groups.

Five patients were on platelet aggregation inhibitors. Levels of sP-selectin were similar in patients that were on aspirin compared to those who were not. Could the authors make some comment about this? Aspirin resistance in this population could be suggested?

Although the size and the characteristics of the study population entail some limitations, it is a good starting point (never addressed before), for further studies with a larger sample.

Competing Interests: No competing interests were disclosed.

\section{I confirm that I have read this submission and believe that I have an appropriate level of expertise to confirm that it is of an acceptable scientific standard.}

Author Response ( F1000Research Advisory Board Member ) 22 Jul 2014

Ton Lisman, University of Groningen, University Medical Center Groningen, Groningen, The Netherlands

We appreciate the interest of the reviewer in our study and thank her for her constructive comments.

1. The suggestion to look at subgroups is appreciated, and we agree that comorbidities such as diabetes and cardiovascular disease may in itself have an effect on levels of endothelial-derived proteins. In addition, we agree that the etiology of liver disease prior to transplant may be of interest (although the patients were only included when they did not have evidence of disease recurrence), and that the different immunosuppressive regimens may have different effects on levels of endothelialderived proteins. However, we feel that the small size of our study doesn't allow for a meaningful subgroup analysis. The normal ranges of the proteins and tests studied are wide already in the general population (also evidenced by the ranges observed in our 30 healthy controls), which indicates that subgroups should be reasonably sized to allow a meaningful subgroup analysis.

2. We agree that the similar P-selectin levels in the patients that were on aspirin therapy may indicate aspirin resistance, although we did not assess platelet function directly and the group of patients on aspirin was small. It has to be noted, however, that the circulating P-selectin is in part also released from endothelial cells, and this process is not expected to be influenced by aspirin. Nevertheless, liver transplant recipients often have multiple factors (diabetes, smoking, hyperlipidemia that may increase the risk for aspirin resistance. To our knowledge there are no published data on the frequency of aspirin resistance in liver transplant recipients or patients with liver disease and such studies will be required to optimize antihemostatic therapy in these patients.

Competing Interests: No competing interests were disclosed. 
Reviewer Report 05 June 2014

https://doi.org/10.5256/f1000research.4265.r4734

(C) 2014 ten Cate $\mathbf{H}$. This is an open access peer review report distributed under the terms of the Creative Commons Attribution License, which permits unrestricted use, distribution, and reproduction in any medium, provided the original work is properly cited.

\section{Hugo ten Cate}

Center for Thrombosis and Haemostasis, Johannes Gutenberg University Mainz, Mainz, Germany

Lisman and colleagues follow up on a number of prior studies of hemostatic and coagulation activity status in patients with liver cirrhosis. In this small study they document the hemostatic phenotype in plasma from 15 patients that had underwent orthotopic liver transplantation (OLT) for liver cirrhosis of diverse nature. In the cross sectional study they compare with healthy persons (of comparable age and sex?).

The main finding is that as compared to healthy persons the 15 patients had elevated plasma levels of von Willebrand factor (VWF), plasminogen activator inhibitor-1 (PAI-1), FVIII and soluble P selection, suggestive of an activated endothelium (and/or activated hemostasis) and an attenuated fibrinolytic system, as shown with clot lysis methodology. Interestingly, thrombin generation parameters were either not different $(\mathrm{F} 1+2)$ or lowered in case of the potential to form thrombin (measured by Calibrated Automated Thrombinography).

The authors conclude that there is evidence of a hypercoagulable state at one year after OLT in these patients, given the above changes, which are suggestive of endothelial activation or damage. A major contributing factor in this process may be the use of immunosuppresive agents.

In addition they document a hypofibrinolytic state.

Minor comments:

Obviously, this study cannot give insight in the origin of the found abnormalities and it is impossible to dissect effects of immunosuppression from those of underlying morbidity; there are several risk factors for CV disease present in this population that may play a role in endothelial activation.

A question would be whether any of these patients had been characterised prior to OLT, since it is known that many hemostatic abnormalities are present in association with liver cirrhosis, as the authors also have documented in previous publications. For instance the high level of vWF must (likely) have been present before surgery so that it remains a question how much of the present findings are due to immunosuppression, or to prior comorbidity?

Also, the comparison with healthy persons from the lab (age? sex?) may suggest that differences in markers are substantial while in part these may be due to young age or healthy status in controls, so the differences attributable to OLT and/or immunosuppression may be smaller when compared to a comparable group of controls, rather than healthy laboratory subjects. 
Interestingly, indeed the hemostatic activation may be counterbalanced by a lowered thrombin generation activity, at least by CAT, so that the net hyper coagulability is somewhat blunted. Given somewhat elevated levels of AT and TFPI, these may explain the lowered ETP and peak levels, but there is no direct evidence that these are the major modifiers in this case.

In summary, this is a small but interesting study, suggesting a prothrombotic plasma phenotype based on activated endothelial markers coupled to a hypofibrinolytic state, related to elevated PAI1. Prospective studies of the actual changes pre and post OLT may be needed to get a better idea of the contribution of comorbidity to these changes, preferably as compared to individuals of similar sex and age. The relevance of the observed changes for predicting the risk of thrombosis in these vulnerable patients is worth pursuing.

Competing Interests: No competing interests were disclosed.

\section{I confirm that I have read this submission and believe that I have an appropriate level of expertise to confirm that it is of an acceptable scientific standard.}

Author Response ( F1000Research Advisory Board Member ) 22 Jul 2014

Ton Lisman, University of Groningen, University Medical Center Groningen, Groningen, The Netherlands

We appreciate the interest of the reviewer in our study and thank him for his constructive comments.

1. We agree that our study is not able to differentiate between the effects of immunosuppression and the effects of comorbidities and smoking on levels of endothelial-derived proteins. We have adjusted the conclusion section to indicate that both immunosuppression and comorbidities may be responsible for the increased levels of endothelial-derived proteins in transplant recipients.

2. The patients were not characterized prior to liver transplantation. Indeed, patients with liver disease have multiple alterations in their hemostatic system which are attributed to defective hepatic synthesis, defective hepatic clearance, consumption, and endothelial activation (which in patients with cirrhosis is strongly related to portal hypertension). Many of the disease-related changes in the hemostatic system are likely no longer present at one year after transplantation in patients with a wellfunctioning graft. Defects in synthesis and clearance are no longer present in patients with a functioning graft, and also portal hypertension will be no longer present. We thus expect the hemostatic changes observed in the present study not to be related to the pre-transplant liver disease, in particular since patients that had disease recurrence were not included in our study.

3. As indicated in our response to the comments of Dr. Gatt, our controls were purposely not matched for age and sex (now indicated in the materials and methods section), and were indeed much younger than the age of our patients. We agree that some of the markers are age-dependent, but the increases observed in endothelialderived proteins are much larger than expected based on age differences only. We 
nevertheless agree with the reviewer that the differences may be slightly overestimated as a result of the age difference.

4. Although we agree that we did not directly show that the decreased thrombin generation in our patients was related to increased TFPI and AT levels, there is evidence that these 2 proteins are important modifiers of the thrombin generation test. We have added a reference to a paper showing the importance of TFPI and AT in determining thrombin generation.

Competing Interests: No competing interests were disclosed.

The benefits of publishing with F1000Research:

- Your article is published within days, with no editorial bias

- You can publish traditional articles, null/negative results, case reports, data notes and more

- The peer review process is transparent and collaborative

- Your article is indexed in PubMed after passing peer review

- Dedicated customer support at every stage

For pre-submission enquiries, contact research@f1000.com 